\title{
Decentralization as ability to adapt
}

Citation for published version (APA):

Birner, J. (1995). Decentralization as ability to adapt. METEOR, Maastricht University School of Business and Economics. METEOR Research Memorandum No. 020 https://doi.org/10.26481/umamet.1995020

Document status and date:

Published: 01/01/1995

DOI:

10.26481/umamet.1995020

Document Version:

Publisher's PDF, also known as Version of record

\section{Please check the document version of this publication:}

- A submitted manuscript is the version of the article upon submission and before peer-review. There can be important differences between the submitted version and the official published version of record.

People interested in the research are advised to contact the author for the final version of the publication, or visit the DOI to the publisher's website.

- The final author version and the galley proof are versions of the publication after peer review.

- The final published version features the final layout of the paper including the volume, issue and page numbers.

Link to publication

\footnotetext{
General rights rights.

- You may freely distribute the URL identifying the publication in the public portal. please follow below link for the End User Agreement:

www.umlib.nl/taverne-license

Take down policy

If you believe that this document breaches copyright please contact us at:

repository@maastrichtuniversity.nl

providing details and we will investigate your claim.
}

Copyright and moral rights for the publications made accessible in the public portal are retained by the authors and/or other copyright owners and it is a condition of accessing publications that users recognise and abide by the legal requirements associated with these

- Users may download and print one copy of any publication from the public portal for the purpose of private study or research.

- You may not further distribute the material or use it for any profit-making activity or commercial gain

If the publication is distributed under the terms of Article $25 \mathrm{fa}$ of the Dutch Copyright Act, indicated by the "Taverne" license above, 


\author{
Jack Birner \\ University of Maastricht \\ University of Trento
}

\title{
1 Introduction
}

The issues of centralization and decentralization are not new in the history of economic and social theory, but lessons from the past tend to be forgotten. I will here discuss some insights of one of the greatest economic and social theorists of this century, F.A. Hayek. Until not so long ago, Hayek's work was almost completely unknown, and the few who knew it were only acquainted with his later writings on social and political philosophy. Hayek's economics remained in the shadow that was cast over it when his one-time opponent Keynes carried the quarter century after the publication of the General Theory in 1936. In this contribution I will show that Hayek's work contains the resources for coming to grips with the problems of centralization and decentralization that are now facing the formerly socialist societies in Eastern Europe. Hayek's technical economics of the 1920s, '30s and '40s will be discussed first. Then I will summarize Hayek's arguments in the debate on a socialist economy, and show how they were generalized into a theory of society. In his later work on the emergence and evolution of social institutions and their relations within society as a whole, decentralized decision making occupies a central position. Hayek's ideas in this domain were shaped by his cognitive psychology, his earliest contribution to the sciences of man. Various Hayekian ideas will be linked to those in other domains with the purpose of examining how we may shed more light on some pressing problems of social organization.

\section{Economic planning}

\subsection{Planning versus the market?}

The difference between socialist and capitalist economies is usually discussed in terms of planning versus the market. But already in the first half of the 1930s Hayek argued that this is a false dichotomy. Hayek had discussed planning in terms which land us right in the middle of the issues of centralization and decentralization. He observed that when analyzing an economic system the relevant question is not whether or not planning takes place. That question is misguided, for planning takes place in every economic system. All economic agents make plans. The relevant question is who is in effective control of the process of making and carrying out the plans. Is it a central planning bureau, or are they the individual decision makers? Economic systems differ according to the extent to which the planning process is centralized. ${ }^{1}$ This way of formulating the problem has far-reaching consequences. If these had been recognized 50 years 
ago, economics might have been an entirely different discipline. Economists, instead of limping along on the crutches of static models when covering dynamic paths, might have developed dynamic models much earlier, they might have recognized the role of expectations much earlier, and instead of dealing with representative agents they might have started analyzing coordination problems. For all of these elements are closely related to the way in which Hayek models the planning process.

\subsection{Plan, equilibrium and time}

Starting from the idea of an plan, Hayek proceeds to construct a dual concept of equilibrium (Hayek, 1928). It comprises both the equilibrium of the individual and that of the economic system as a whole. For an individual Hayek defines equilibrium as the state in which the data of his economic plan correspond to his expectations (ibid., p. 38-9). The data are the individual's own preferences and the plans of other individuals. Or rather the actions undertaken as a consequence of these plans and as perceived by other individual planners. When the perceived actions are in accordance with the actions as expected by everybody, no-one's expectations are falsified. Hence, no-one has an incentive to change his plan. The plans of all individuals are consistent with one another. In other words, they are coordinated, and the economic system as a whole is in equilibrium. This dual formulation of equilibrium applies both to a centrallydirected economy and a market system.

Equilibrium is a relation between actions, and the actions of an individual follow one another in time. Every individual compares the actual level of the satisfaction of his needs with the desired one. In his evaluation he includes the means available to satisfy his needs. Time separates the actual state of affairs from the desired one. Hence every plan involves a time interval, and there is no plan without time (Hayek, 1937, p. 367). Hayek's way of modelling equilibrium entails that equilibrium analysis is not restricted to a static or a stationary system. Whether the economy is stationary, grows, or shrinks depends on the expectations of the individuals of which the system is made up (ibid., p. 41). If every economic agent expects a particular rate of growth, equilibrium is preserved as long as there are no signals that are inconsistent with these expectations. Equilibrium does not mean the immutability of objective data, but the fulfillment of subjective expectations.

\subsection{Disequilibrium}

Plans are based on knowledge and expectations. A change in the expectations of some planner will lead him to change his course of action. This will generate signals that change the informational input of other planners. A dynamic theory is needed to describe the processes that operate in the system after the state of equilibrium has been disturbed. During the 1930s Hayek developed such a theory to explain business cycles. Individuals base their actions on perceived prices, i.e., money prices. If, 
however, changes in the money supply do not keep exact pace with changes in the real relative scarcities of goods and services, perceived money prices do not correspond to real relative prices. According to Hayek, credit money is a systematic source of disturbances, and these may be aggravated by occasional monetary interventions by governments. As a consequence of these disturbances, individuals take the wrong consumption and investment decisions. This causes changes in the structure of capital and production that do not correspond to changes in real intertemporal relative scarcities. It is not until the output that is produced by the changed production structure is confronted with the demand by consumers that it is discovered that there is a mismatch. The structure of production is readapted, which involves capital destruction and unemployment. The result is a series of cyclical movements in the level of investment. Hayek spent most of the $1930 \mathrm{~s}$ to work out the capital-theoretic foundations of his theory of industrial fluctuations. This culminated in the publication of Pure Theory of Capital in $1941 .^{2}$

Implicit in Hayek's business cycle theory is a theory of social learning. The changes in the structure of production impose constraints on the individuals' possibilities for realizing their plans. When running up against these constraints they learn that their plans cannot be realized - the hard way. ${ }^{3}$ Due to the locality of individual perception (or the existence of distributed, limited knowledge), a learning process is needed to force individuals to do what they would have chosen to do had they been in a position to take the correct decisions to begin with. This process is a social learning process in that constraints that emerge out of the interaction of individuals force individuals to adapt their plans. It is in this sense that the system 'knows' more than the individuals of which it consists.

\subsection{Socialism}

After the resounding success of Keynes' General Theory, Hayek started to withdraw from analytical economics. In so far as he was still remembered, it was for his contributions to the debate on the feasibility of socialism. Even so, his arguments did not play any part in the analysis of centrally-planned economies until recently. For the purposes of the debate of the 1930s Hayek defined socialism as central planning by the government. ${ }^{4}$ His criticism of a socialist economy is that it is informationally inefficient in three ways. First, the millions of individuals who together make up an economy know their own specific circumstances in quite some detail. However, a centrally-planned economy lacks the means of collecting all these individual bits and pieces of information. Second, under a system of centralized decision making there are no incentives for individuals to discover new opportunities. And third, even if a central planning bureau had the means of collecting all relevant information, the computational demands would supersede the capacities of even the fastest computers. Although in the debate Hayek had concentrated on the economic arguments, he had made it clear that this was too 
narrow a perspective. His subsequent development may be seen as an attempt to supplement the economic arguments against a socialist economy with arguments about the social framework of an economy.

\section{From economics to theory of society}

Though forgotten by others, the basic messages of Hayek's economics were not lost forever. For after Keynes' victory, Hayek proceeded to develop a theory of society and of social institutions which is a generalization and an elaboration of his ideas about the mechanisms that regulate an economy. Even though these later theories never reach the heights of analytical sophistication of his economics, they contain enough that is of interest for the study of centralization and decentralization today. In a series of books and articles, Hayek developed his ideas about social learning and the evolution of institutions and the way in which markets and competition function. ${ }^{5}$

'Individualism True and False' of 1945 (ITF) $^{6}$ is a focal point in the generalization of Hayek's thought from the domain of economics to that of social theory. ITF works out the consequences of the theory of society of the philosophers of the Scottish Enlightenment. According to Hayek, 'its basic contention is (...) that there is no other way toward an understanding of social phenomena but through our understanding of individual actions directed toward other people and guided by their expected behavior.' (ITF, p. 6).

The individualism of the scottish philosophers has to be distinguished from the so-called individualism of the Cartesian school, which is usually referred to as rationalism. This is why Hayek calls the true individualism of the Scottish Enlightenment anti-rationalism.

'The antirationalistic approach, which regards man not as a highly rational and intelligent but as a very irrational and fallible being, whose individual errors are corrected only in the course of a social process, and which aims to make the best of a very imperfect material, is probably the most characteristic feature of English individualism.' (ITF, p. 8-9)

This insight is due to Mandeville. True individualism is closely connected to classical political economy. The great discovery of the classical economists was that 'many of the institutions on which human achievements rest have arisen and are functioning without a designing and directing mind (...) and that the spontaneous collaboration of free men often creates things which are greater than their individual minds can ever fully comprehend.' (ITF, p. 7)

Contrary to the pseudo-individualism of the rationalists and social engineers, 'true individualism is the only theory which can claim to make the formation of spontaneous social products intelligible' (ITF, p. 10), and it 'believes (...) that, if left free, men will often achieve more than individual human reason could design or foresee.' (ITF, p. 10-11).

These ideas were applied to the domain of politics, where they 
were used for designing 'a system under which bad men can do least harm.' (ITF, p. 11). ${ }^{7}$ But true individualism is more than a political doctrine. It is a theory of society as a whole. Underlying this theory of society is

'a view which in general rates rather low the place which reason plays in human affairs, which contends that man has achieved what he has in spite of the fact that he is only partly guided by reason, and that his individual reason is very limited and imperfect... One might even say that the former is the product of an acute consciousness of the limitations of the individual mind which induces an attitude of humility toward the impersonal and anonymous social process by which individuals help to create things greater than they know (...).' (ITF, p. 8)

Such a theory needs to find an answer to the question of what keeps a society together. The answer is that social cohesion is a matter of an adequate institutional framework, one, moreover, which does not rely for its operation on the application of outside force: 'The great concern of the great individualist writers was indeed to find a set of institutions by which man could be induced, by his own choice and from the motives which determined his ordinary conduct, to contribute as much as possible to the need of all others (...).' (ITF, p. 12-13)

Two central ideas mark Hayek's transition from economics to the theory of society. One concerns 'the constitutional limitation of man's knowledge and interests, the fact that he cannot know more than a tiny part of the whole of society and that therefore all that can enter into his motives are the immediate effects which his actions will have in the sphere he knows.' (ITF, p. 14) The other idea is the description of social institutions as problem solvers. Social institutions solve the problem of complexity, a problem that Hayek came to address in more general terms in his philosophy of science of the late $1950 \mathrm{~s}$ and early 1960s.8 The philosophers of the Scottish Enlightenment had argued that institutions are capable of performing tasks that are far too complex for individual human minds. Following their ideas, Hayek sees social institutions as undesigned, spontaneously grown interaction patterns, or rules, that by discovering and coordinating dispersed knowledge reduce the complexity facing individuals with limited knowledge and thus allow their actions to be coordinated. These rules are largely implicit in that they contain the accumulated tacit knowledge of past generations.

\section{Cognitive and social systems}

\subsection{Learning and rationality as social phenomena}

That the transition of Hayek to social philosophy involves a generalization of his ideas on economics, is confirmed by what Hayek says in ITF: 'What the economists understood for the first time was that the market as it had grown up was an effective way of making man take part in a process more complex and extended than he could comprehend and that it was through the market that 
he was made to contribute to "ends which were no part of his purpose."' (ITF, p. 14-5)

Hayek acknowledges that these economists had found a theory of social learning. The belief in a theory of social learning is consistent with the idea that rationality is a social phenomenon.

'The true basis of [the individualist's] argument is that nobody can know who knows best and that the only way by which we an find out is through a social process in which everybody is allowed to try and see what he can do. The fundamental assumption, here as elsewhere, is the unlimited variety of human gifts and skills and the consequent ignorance of any single individual of most of what is known to all the others members of society taken together. Or, to put this fundamental contention differently, human Reason, with a capital $R$, does not exist in the singular, as given or available to any particular person, as the rationalist approach seems to assume, but must be conceived as an interpersonal process in which anyone's contribution is tested and corrected by others.' (ITF, p. 15 )

This process generates the tacit knowledge which makes society function, and this tacit knowledge is embodied in a particular institutional structure. Obstructing the spontaneous interaction of individuals hampers the growth of this type of knowledge: '[the] desire to make everything subject to rational control, far from achieving the maximal use of reason, is rather an abuse of reason based on a misconception of its powers, and in the end leads to a destruction of that free interplay of many minds on which the growth of reason nourishes itself.' (Hayek, 1964, p. 93).

\subsection{Cognitive psychology and social theory}

In 1920, at the age of 21, Hayek had written a manuscript that contains the theory of cognitive psychology which was not published until 1952, in an extended version, as The sensory Order (SO).9 I will discuss Hayek's psychology because it is closely linked to his later theory of society.

Hayek assumes that there are two 'orders' in which the human mind arranges the objects in the world: the physical order, which classifies external events as similar or different according to whether they produce similar or different other external events; and the sensory order, which classifies events according to their sensory properties. In contrast to Ernst Mach, Hayek holds that there is no simple one-to-one correspondence between the elements of the two orders. This criticism of Mach was the reason why Hayek developed his cognitive psychology (cp. De Vries, 1994). Events which appear to our senses to be of the same kind, may be different in the physical order, and the other way around. The relation between the sensory order of the human mind (the 'microcosm') and the physical order of external events (the 'macrocosm') is the central problem of SO.

The principal tenet of the book, which also constitutes its 
main difference with other psychological theories, is that

'the sensory (or other mental) qualities are not in some manner originally attached to, or an original attribute of, the individual physiological impulses, but that the whole of these qualities is determined by the system of connexions by which the impulses can be transmitted from neuron to neuron; that it is thus the position of the individual impulses or group of impulses in the whole system of such connexions which gives it its distinct quality; that this system of connexions is acquired in the course of the development of the species and the individual by a kind of 'experience' or 'learning'; and that it reproduces therefore at every stage of its development certain relationships existing in the physical environment between the stimuli evoking the impulses.' (SO, 2.49)

There are no pure sense data or facts, but all facts are embedded in a complex of relations to other facts, which we may call, in the terminology of SO, a 'map'. From this map, which serves as a kind of first approximation, more permanent sets of classifications are formed. Hayek calls these 'models'.

'It is (...) the process of multiple classification which builds the model. What we have before called the 'map', the semi-permanent apparatus of classification, provides the different generic elements from which the models of particular situations are built. The term 'map', which suggests a sort of schematic picture of the environment is thus really somewhat misleading. What the apparatus of classification provides is more a sort of inventory of the kind of things of which the world is built up, a theory of how the world works rather than a picture of it. It would be better described as a construction set from which the models of particular situations are built.' $(\mathrm{SO}, 5.89)$

These models are not complete representations of the world.

That it is possible for the mind to build representations of the physical order from a set of models that is necessarily limited, is due to the accidental fact that the structure of the world is 'redundant', to use Herbert Simon's term: ${ }^{10}$

'It is (...) no more than a fortunate accident that the different events in the macrocosm are not fully interrelated to any significant degree, but that as a rule it is possible to base predictions of certain kinds of events on a mere selection of a totality of events.' (SO, 5.90)

Hayek's psychology is an evolutionary theory. The idea that the human mind evolves as part of man's struggle for survival dictates the problem: 'Our task is (..) to show in what sense it is possible that within parts of the macrocosm a microscosm may be formed which reproduces certain aspects of the macrocosm and through this will enable the substructure of which it forms part to behave in a manner which will assist its continued existence.' (SO, 5.78) The mind works through a continuous process of classification and reclassification of sense impressions and the 
classifications formed from them. This takes place in the central nervous system, which is involved in a continuous process of self-organization. This leads to an ever more complex set of classifications in the shape of increasingly intricate patterns of connections between neurons. This evolutionary process is what the working of the mind consists of. To perceive is to classify sense impressions along neural routes that become more and more firmly established, and that in the end no longer have to be adapted any further. In a term that has become common with the work of Simon, we may call these routines.

This argument in Hayek's cognitive psychology has a parallel in his theory of society. A developed society has to a large extent become 'routinized'. This is a characteristic of what Hayek calls the 'extended order' of society. The spontaneously evolved social institutions contain a surplus of tacit over explicit knowledge. As Keizer writes: 'Civilization advanced by increasing the number of operations mankind performs without thinking about them. (Keizer, 1994, p. 216). We may observe that this is a mixed blessing. On the one hand, the advanced level of routinization liberates much social energy for creative innovation of the institutional structure. On the other hand, the progress of routinization also makes it ever harder to change what has grown. Hayek argues that any intervention in these institutions may have unintended consequences, ones that may eventually lead to their total destruction. ${ }^{11}$

This parallel between Hayek's psychology and his theory of society is not an isolated instance. There are many more homeomorphisms. This is not so strange as it might appear if one keeps the following in mind. In Hayek's work, the theme of communication is a crucial intermediate step between his economics and his later theory of society as a whole: 'Economics and Knowledge' of 1937, with a later follow-up in 'The Use of Knowledge in Society' of 1945, and 'Competition as a Discovery Procedure' of 1968. In his contributions to the socialism debate communication failures are crucial, as is the case with his business cycle theory. The response of an economy to these communication failures constitutes a process of social learning. Also of relevance is that for the better part of his active intellectual life, Hayek was looking for solutions to the problem of explaining collective effects from individualist premises. Thus, a major part of Hayek's efforts in developing his economics during the 1930s went into reducing the macro-economic phenomenon of the business cycle to the micro-economic theory of rational choice. The same type of problem is central to his investigations in psychology, viz. finding the relation between the microcosm of the human mind and the macrocosm of external events. Hayek's resuming work on his cognitive psychology made him see the role of collective effects, and more in particular social institutions, in a new light.

'When I look back, it seems all to have begun, nearly thirty years ago, with an essay on 'Economics and Knowledge' in which I examined what seemed to me some of the central difficulties of pure economic theory. Its main conclusion was that the task of economic theory was to explain how an overall order of economic activity was achieved which utilized a large amount 
of knowledge which was not concentrated in one mind but existed only as the separate knowledge of thousands or millions of different individuals. But it was still a long way from this to an adequate insight into the relations between the abstract rules which the individual follows in his action, and the abstract overall order which is formed as a result of his responding, within the limits imposed upon him by those abstract rules, to the concrete particular circumstances which he encounters.' (Hayek, 1965 91-2)

And in the third volume of Law, Legislation and Liberty of 1979 Hayek remarks:

\begin{abstract}
'the work on it [SO] has helped me greatly to clear my mind on much that is very relevant to social theory. My conception of evolution, of a spontaneous order and of the methods and limits of our endeavours to explain complex phenomena have been formed largely in the course of the work on that book. As I was using the work I had done in my student days on theoretical psychology in forming my views on the methodology of the social science, so the working out of my earlier ideas on psychology with the help of what I had learnt in the social science helped me greatly in all my later scientific development.' (p. 199, n. 26)
\end{abstract}

\title{
4.3 A reliable system from unreliable parts
}

Hayek's argument that rationality is the property of a social system, and that such a system is more stable and reliable than a collection of unconnected rational individuals is reminiscent of Simon's remark on the reliability of computers: 'The question is how to build a reliable system from unreliable parts. (...) We can cope with unreliability only by our manner of organizing them.' Simon, 1969, p. 19). If we do not read Simon's 'organize' in the sense of consciously creating a system, the above ideas of Hayek and Simon amount to the same. This is no coincidence. Simon is a cognitive psychologist and a pioneer in linking the analysis of human cognition and computer science. In that field, neural network theory plays a prominent part. Hayek's so was one of the sources from which of neural network theory was developed. ${ }^{12}$ These common roots explain why there are often such striking resemblances between neural networks and Hayek's spontaneous-order model of society. To give just two instances, McClelland et.al. (1986, p. 3) answer the question 'What makes people smarter than machines?' by observing that 'people are smarter than today's computers because the brain employs a basic computational architecture that is more suited to deal with a central aspect of the natural information processing tasks that people are so good at.' (ibid.) Hayek's answer to the analogous question in the domain of society is that it is the social structure that is important, i.e., the interaction patterns which make markets so much more efficient than the essentially sequential and hub-like processes and structure of central planning.

Another instance is the modelling of learning in neural networks 
as the strengthening of connections between neurons. This has its counterpart in Hayek's idea that successful interaction rules will be repeated more often than less successful ones and become embodied in the tacit knowledge of social institutions. Another connection-strength model is to be found in sociological network theory, which will be discussed below.

\subsection{Incentives}

In his contribution to the debate on socialism, Hayek did not elaborate the problem of incentives as requisites for the working of the market. Ludwig von Mises did. Mises defined socialism as state ownership of the means of production and his criticism focuses on the absence of private property rights that characterize a socialist society. As individuals neither gain nor lose as a direct consequence of their own decisions, they have no incentives to balance costs and revenues optimally. This entails that under socialism no real scarcity prices are established, which in their turn are a necessary ingredient for rationally calculating decision makers. Without private property there is no rational calculation.

On the level of the social system, incentives play a part which is not related to rational calculation but to the cohesion of a social system as a whole in the face of the existence of opposing interests. Adequate incentives are required for maintaining social cohesion; individuals in a society must be motivated to co-operate. For a particular institutional framework to be stable, a mechanism is needed through which it reproduces itself over time. Marina Bianchi has formulated this problem as the following paradox: when interests are opposed 'private interests cannot be generalized without losses, and what can be generalized (moral codes) does not obey private motivations.' (Bianchi, 1994, p. 243). Neither Mises nor Hayek explain how opposing interests can be reconciled. Unless this problem is solved, a system in which individual knowledge and actions are co-ordinated and rational calculation takes place is not even likely to arise, or if it arises, is not likely to be stable. The analysis of prisoner-dilemma situations has made it clear that in situations in which everyone rationally pursues his own private interests and searches his own individual gain, no social rules may arise without generating mutual losses. Even in the situation of a repeated prisoners' dilemma there is no guarantee of a cooperative outcome, i.e. a stable system of social rules. And even when an agreement to co-operate should arise spontaneously, some enforcement rules have to be discovered for the interaction pattern to be stable: 'without an evolved and continuously adjusting system of enforcement rules, conflictual interests will prevail.' (ibid., p. 244).

Bianchi argues that Hayek's theory of competition as a dynamic discovery procedure contains the elements for an explanation of both the coordination and the incentive effects. Hayek thinks of competition as a discovery process which is instrumental in coordinating individual actions. However, competition has another function, too. It provides the incentives for outcompeting rivals. This may have positive external effects. 
'Competition is not only the place for arbitrage gains, for "stepping in" and grasping first an opportunity (...), but also searching for, and the means of rewarding, new forms of gain. (...) Vices are not replaced by virtues; they remain vices, only they become more sociable in their effects. Nothing guarantees that this form of socialization proceeds steadily and irreversibly (...) But the learning procedure that is implied in the process will provide the flexibility for adjustments and corrections. The meaning of "order" changes; it is not a state of affairs, but a process; not a correct state, but a corrigible one.' (ibid., p. 245)

The appropriate institutional framework for the market is as much object of continuous discovery as the market opportunities themselves:

'On the one hand, a complex system of moral codes, rules of fairness, as well as an articulated system of punishments for the violators, has to be continuously discovered and adjusted. On the other hand, the search for competitive gains must always find new channels. In this different setting the market game, Hayek's game of catallaxy not only teaches the players how to transform the enemy into friend (...), it also provides the incentive structure to discover and reward more social ways of "defection"'. (ibid., 246)

\section{System and individual}

\subsection{Levels of analysis}

In the above, the possibility was mentioned that an entire social structure is more reliable than the individual units of which it is made up. Closely related to this scientific question is the methodological problem of the basic unit of analysis, or the correct level of aggregation. In his early work Hayek was a staunch defender of methodological individualism. However, he gradually abandoned the individualist methodology for a holistic one, probably under the growing influence of evolutionary ideas in his social theory. After The constitution of Liberty of 1960, the evolution and selection of institutions are no longer described in terms of a mechanism that are consistent with methodological individualism. Hayek became alienated, so to speak, from the individualism of the Scottish philosophers, which he had held up as a shining example. His later theory of the evolution of institutions relies on a holistic concept of group selection. This is a vague notion that has kept Hayek from solving the problem what incentives it would take to make individuals adopt rules that, though conflicting with their selfinterest, have survival value for the social order as a whole.

Bianchi returns to Hayek's former individualism. She retains the core of his evolutionary ideas on social institutions without the conservative conclusions Hayek himself drew from them. She shows that there is no need for holistic elements such as group selection. She improves on Hayek on several more issues. She explains learning behaviour, which Hayek had not addressed, in 
terms of the incentives provided by the prospect of competitive gains. Moreover, she proposes a more satisfactory criterion for measuring the selective evolutionary advantage of a particular social system. It is the ability to learn which constitutes a selective evolutionary advantage of a society instead of the criterion which Hayek puts forward in his Fatal conceit, which is the number of people a society can keep alive. Bianchi's is a process criterion which is more consistent with Hayek's rejection, in is earlier work, of end state criteria. But the main advantage of Bianchi's proposal of linking social selection to learning is that it may assist us in finding ways of implementing a selection mechanism that may benefit all members of a society. This will be elaborated below.

\subsection{Social learning}

There are two main aspects to the ability to learn in a social structure. One is that of discovery, the other of the transmission of knowledge. Theories about these aspects come in two varieties: ones that emphasize structural mechanisms, and others that analyze these aspects in terms of the actions of individuals.

A 'structural' theory of discovery can be found in Mises' discussion of the role of the entrepreneur in his contribution to the debate on socialism. Mises stresses the importance of positions in a social structure: 'Like Plato's philosophers, the directors so appointed [i.e. in public enterprises] may well be the wisest and best of their kind, but they cannot be merchants in their posts as leaders of a socialist society, even if they should have been previously.' (Mises, 1920, p. 121). This is because '[a] merchant's qualities are not the property of a person depending on inborn aptitude, nor are they acquired by studies in a commercial school or by working in a commercial house.... The entrepreneur's commercial attitude arises from his position in the economic process and is lost with its disappearance.' (ibid.).

In a more sophisticated form we find a similar structural view of entrepreneurship in Ronald Burt's Structural Holes; The Social Structure of Competition. Burt models the economy as a network of agents who are linked to one another. There may be connections that are possible yet have not been realized. Burt calls these 'structural holes'. In this analysis,

'competition is a matter of relation, not player attributes. The structural hole argument escapes the debilitating social science practice of using player attributes for explanation. The relations that intersect to create structural holes give a player entrepreneurial opportunities to get high rates of return. The player in whom the relations intersect - black, white, female, male, old, young, rich, poor - is irrelevant to the explanation. Competition is not about being a player with certain physical attributes; it is about securing productive relationships. Physical attributes are a correlate, not a cause, of competitive success. Holes can have different effect for people with different attributes or for organizations of 
different kinds, but these differences in effect occur because the attributes and organization forms are correlated with different positions in social structure. The manner in which a structural hole is an entrepreneurial opportunity for information benefits and control benefits is the bedrock explanation that carries across player attributes, populations, and time.' (Burt, 1992, p. 4)

Notice that Burt adds to the Hayekian theme of information ${ }^{13}$ that of control. This opens the way to an analysis of dominance and power in markets that is lacking in Hayek.

The transmission aspect of social learning involves the ability of that structure to transmit information efficiently and without distortion. This is a topic that has been studied extensively in sociological network theory, and more in particular in the tradition of which Mark Granovetter is a prominent theorist. In what is known as the strength-of-weak-ties argument one may see an elaboration of the idea that is to be found in Hayek that the transmission of information has to do with the overlapping domains of perception of individuals. ${ }^{14}$ In network theory this is known as connectivity. I derive the following version of the argument from Flap, 1976.

The basic assumption of the argument is that differences in communication behaviour are caused by differences in social networks. In their turn, the characteristics of networks are defined in terms of the attitudes of the individuals of which the network is made up. individuals have various types of ties with one another. The intensity of the ties determines both the nature and the frequency of the interactions. Ties are distinguished in terms of the differences between individuals as similar or homophilous and dissimilar or heterophilous. It is assumed that homophily is correlated positively with strong ties and heterophily with weak ties. Another dimension of interactions or relationships is their multiplicity, i.e. the number of different social roles in which individuals interact. Multiplicity is positively correlated to strength. So we arrive at the hypothesis that the greater the number of social roles in which agents interact, the stronger their ties.

Then Flap introduces the notion of cognitive dissonance, with intensity and frequency as dimensions. These are linked to the strength of ties as follows. The stronger an individual's emotions, the stronger the dissonance; the stronger the dissonance, the more will information be distorted; the stronger the ties, the stronger the emotions; hence, the stronger the ties, the more does information become distorted. The frequency with which information is distorted is introduced in a similar way. The more often new information is offered, the more often will there be cognitive dissonance; the more frequently there is dissonance, the more often will there be distortion of information; the stronger the ties, the less often will there be dissonance; hence, the stronger the ties, the less frequently will information be distorted.

Taken all together, these steps lead to the prediction that in the case of homophilous or strong ties, more limited information which is strongly distorted will be distributed less frequently over fewer agents. Finally, the openness of a network (i.e., 
measure in which it consists of elements with weak ties) is linked to the open-mindedness of agents (agents are more tolerant of cognitive dissonance). Thus one arrives at the following theoretical prediction. The more a society consists of networks that are characterized by weak ties, the faster will more comprehensive and less distorted information be distributed over more agents who are more tolerant. Conversely, the more a society is characterized by closed or strong-tied networks, the more slowly will less comprehensive and more distorted information be distributed over fewer agents and agents who are less tolerant.

The above version of the strength-of-weak-ties argument offers a fruitful generalization of Hayek's argument about markets and the price system as communication mechanisms. This deserves more comment than I can devote to it here, but I will just draw the attention to the element of cognitive dissonance. Hayek defines the equilibrium of the individual as the state of affairs in which the individual's expectations are not falsified. This can straightforwardly be reformulated as the absence of cognitive dissonance. The strength-of-weak-ties argument was originally developed for labour markets. It is strange that with one recent exception it has never been generalized to an analysis of the functioning of all markets. ${ }^{15}$ What it has been applied to, in sociology, are matters of social stability. According to the Granovetter approach, social relationships become more stable if individuals enter into multiple and weak social relationships with one another. This would explain why the communist societies of Eastern Europe that had long since gone bankrupt in reality functioned tolerably well. Their citizens entertained many more relationships with one another than the official blueprint of society showed and allowed.

\subsection{Structure versus individual?}

Both Burt and Bianchi describe a social discovery process, but the objects of discovery differ. Burt emphasizes the purely structural phenomena of missing links or 'holes', which are bridged by entrepreneurs. Bianchi speaks of new forms of interaction. These have to do with the rules and motivations governing the behaviour of individuals, from which Burt abstracts on purpose (Burt, 1992, p. 35). In explaining competition it does not seem necessary to make this mutually exclusive choice between individuals' characteristics and their structural position. As Hayek observes in his writings on rule-guided behaviour, individuals have certain dispositions which have to be activated. A rule is a disposition (Hayek, 1969, p. 43), a 'movement pattern (...), ordering principle' (Hayek, 1963, p. 45), 'a statement by which a regularity of the conduct of individuals can be described' (Hayek, 1976a, p. 67). A rule can be conceived of as a model of behaviour or a law of individual behaviour (cp. also Hayek, 1963a, p. 37). Rules are no sufficient conditions for behaviour; they have to be activated by 'a particular external stimulus or (...) an internal drive' (Hayek, 1963a, p. 69). The behaviour stops when the stimulus ceases to be operative. In a social system the original stimulus may be deactivated by coordination. 
'The orderliness of the system of actions will in general show itself in the fact that actions of the different individuals will be so coordinated, or mutually adjusted to each other, that the result of their actions will remove the initial stimulus or make inoperative the drive which has been the cause of activity.' (Hayek, 1963a, p. 69)

If one realizes that the sort of stimulus an individual receives will be largely dependent on his location in the social structure (which influences his perception of signals), this seems like a perfectly satisfactory way of integrating (individual) function with (position in a) structure. This is consistent with the methodologically individualist Granovetter tradition.

\section{Past before present}

\subsection{Prediction and stability}

Bianchi's message of social order as the ability to learn is reminiscent of the pre-conservative Hayek of Constitution of Liberty of 1960. In that book Hayek argues that social innovation is necessary for a social order to survive. The creation of new rules that compete for the favour of society keeps that society from becoming fossilized in its old ways when the environment changes and calls for new ways to cope with problems of complexity. But how to create the conditions that favour competition? Or more generally, how can we implement the idea of social order as ability to learn? It would be contrary both to the nature of the competition process and to the evolutionary spirit of Hayek's social theory to think that this can be achieved by imposing a detailed set of conditions.

Hayek's methodology offers some guidance. In the $1950 \mathrm{~s}$ and 1960 s Hayek explicitly dealt with problems of complexity, both as a phenomenon in the social world and as a problem for the theory of science. He argues as follows. Even if we, as social scientists, know the laws that are relevant for predicting social situations, we cannot know all the relevant initial conditions. Therefore, detailed predictions are beyond our reach. This implies that detailed social engineering is out of the question. The most we can attain is that we may sometimes, when we know the relevant regularities, predict that particular global situations cannot occur together. Particularly in his later work, after 1960, Hayek is rather radical in the way in which he interprets this. Instead of thinking in terms of trade-offs, for example between more and less centralized planning, he constructs pairs of mutually exclusive states of the world. This is related to the fact that Hayek conflates the notion of unintended with that of unpredictable. This is noticed by Plant, ${ }^{16}$ who argues that whereas income redistribution may have unintended consequences for the functioning of the market, these consequences are not necessarily unpredictable. This is all for the better because it may be necessary for the introduction and the stability of a market system to 'buy the loyalty' of those who are dissatisfied with the outcome of the market process. Predicting the 
consequences of redistribution may help us determine the measure to which incomes can be redistributed without destroying the system. The 'solution' Hayek offers is a moral one. The only thing we can do to preserve the market in the face of demands for redistribution is to educate the individuals within a market society into accepting that the outcomes of market processes may not be just.

It is much more fruitful to formulate problems such as these in more general terms. Constructing a theory that takes possible trade-offs into account is an advance from a scientific point of view as it leads to non ad-hoc explanations. For instance, instead of asking why the introduction of some central planning leads to complete centralization, one may ask if there exists a stable mix between centralized and decentralized decision making. If one reads Hayek's work in this way, several other trade-offs may be found that are relevant for transition problems, such as individual planning as compared to central planning, changing a social structure according to a blueprint as compared to change by spontaneous evolution. Underlying the latter is the more general problem of the correct mix of conservatism and innovation. Another possible trade-off may concern dispersed knowledge which must be coordinated as compared to knowledge which is more generally available and needs less coordination

Let me return to prediction and stability. There is a different level on which predictability matters. For the participants in social processes predictability is an important condition for stability. To a certain extent this can be furthered by legal measures. The co-ordination of knowledge without the resulting 'contracts' being enforceable would not work. The crux of smallunits capitalism is that there is a lot at stake for all the decision making units when they enter into relationships with others. The situation is typically not one of a one-shot prisoners' dilemma (even though many small entrepreneurs behave that way. According the Granovetter approach, relationships become more stable if units enter into multiple relationships with one another. This is another feature of a social framework that one might conceivably enhance: make sure people encounter each other in as great a number of different roles as possible. This makes for more tolerance, more stability and more open networks, hence for more opportunities for social learning.

\subsection{Myths about markets}

The discussion about the desirability and the feasibility of introducing a decentralized market society in Eastern Europe has been obscured by the habit of comparing actual centrally-planned economies with an idealized market economy. Unfortunately, this idealized picture is about all we have. We just do not know how markets really work. The analysis of markets as it is conducted by traditional mainstream economics is a travesty of understanding. To begin with, they drew any teeth their theory might have had by defining equilibrium tautologically as a state of perfect information (cp. Hayek, 1937, p. 42). They ignored the essentially dynamic character of competition by searching for static conditions under which particular market forms 
(misleadingly referred to as various types of competition) may exist. And they built models that pretended to give an individualist behavioural foundation to an analysis of a market system around a representative individual, thus excluding any role for information, coordination, communication or the organization of the economy. There is even no exchange. ${ }^{17}$ But the feature of neoclassical Walrasian general equilibrium theory that probably renders it most useless for understanding markets is that it is based on the assumption of an interaction structure that does not fit a market economy. As Kirman observes (Kirman, 1983), the structure of a Walrasian economy is star-shaped. All transactions are modelled as being conducted via a central auctioneer. This is the structure of a centrally-planned economy, and it is paradoxical to apply this structure to a market economy, which has the structure of a network of multiple relations among individuals. Equally paradoxical is the fact that the only economy to which the standard neoclassical model applies straightforwardly is a centrally-directed dictator economy. It is only in a centrally-planned economy, where allocation and price formation is centralized, that the neoclassical allocation mechanism applies in its full force. ${ }^{18}$ But 'once we break away from the "star-like" structures of a classical economy with central auctioneer, who trades with whom, and who passes information to whom becomes very significant.' (Kirman, 1983, p. 107).

Paradox was turned into scandal when the millions of dollars the West made available to help the former communist countries create a market society were spent in the same West on hiring the preachers of this sterile mainstream economic doctrine.

Given the centralized star structure such as a Walrasian or a socialist economy, it is reasonable to assume that individuals are connected by non-multiples, strong ties. The work of Granovetter and others teaches us that from a communication viewpoint such a social structure 'will be fragmented and incoherent. New ideas will spread slowly, scientific endeavors will be handicapped, and subgroups that are separated by race, ethnicity, geography, or other characteristics will have difficulty in reaching a modus vivendi.' (Granovetter, 1982, p. 106). This is in stark contrast to the virtues that the neoclassical defenders of a market society claim for it.

The weak-ties analysis also suggests an explanation for the recent manifestations of ultra-nationalism in Eastern Europe. Lacking a network consisting of weak ties, the central authority of the communist societies needed a strong repressive apparatus to suppress the forces counteracting cohesion. As soon as that authority lacked the means for repression, many societies in the East fragmented into sub-units.

In the above, I have defended the view that markets should be considered as social networks. I now want to briefly draw the attention to two other aspects of markets. First, markets, like other social networks, are constructs. They are social constructions in two senses. One is that markets only exist by virtue of the beliefs of individuals; this is directly related to the fact that the perception by an individual is partly a result of his development, which in turn incorporates a learning process. Hence, whether a particular market exists and is stable 
(i.e. reproduces itself $f^{19}$ ) is dependent on learning processes. This is of direct relevance to Eastern Europe. Unless people have the opportunity to learn to play the social roles of which market relations consist, no market society will be established. The second sense in which markets are social constructions is that they are the result of a historical process of development which is in large part unplanned or spontaneous. ${ }^{20}$ The fact that in such a process there may have been episodes of deliberate intervention does not defuse this argument. ${ }^{21}$

The other feature of markets that I want to mention involves the idea of collective or public goods. For their functioning and stability markets rely on the existence of public goods such as money and a legal framework. ${ }^{22}$ Defenders of the idea that markets arise out of individuals' perfectly free pursuit of nothing but their self interest are defending a myth. In so far as they invoke Adam Smith as their patron saint, they should know better. True, in The Wealth of Nations Smith focuses his analysis on self interest as motivating human action. But he is also the author of an earlier book, The Theory of Moral Sentiments. Its first sentence is:

"How selfish soever man may be supposed, there are evidently some principles in his nature, which interest him in the fortune of others, and render their happiness necessary to him, though he derives nothing from it, except the pleasure of seeing it." (Smith, 1759, p. 47)

Smith develops the theory that disrespect for one's fellow citizens makes a society unstable.

'Society may subsist among different men, as among different merchants, from a sense of its utility, without any mutual love or affection; and though no man in it should owe any obligation, or be bound in gratitude to any other, it may still be upheld by a mercenary exchange of good offices according to an agreed valuation.

Society, however, cannot subsist among those who are at all times ready to hurt and injure one another.' (Smith, 1759, p. 166)

In some former communist countries there are currently many indications of a form of pirate capitalism under which partners in market transactions only seek their own short term gain. These instances show that Smith's important lesson still has to be learned. Smith is opposed to the idea, which he attributes to Mandeville, of man as only heeding his self interest in his relationships with other men. Clearly, there is a tension between Smith's criticism of Mandeville's idea of competition and Bianchi's interpretation. According to Smith, a society could not persist on the basis of a Mandevillean motivation of individuals. Bianchi, on the other hand, stresses the discovery aspect of this behaviour and argues that the learning process engendered by it makes for a dynamic type of social stability. One way to resolve this tension is to attribute to competitors the awareness that they all benefit from keeping the broad institutional framework intact which allows them to compete and benefit from others. 
Thus, we have arrived at the second way in which collective goods are involved: markets themselves are collective goods. Markets emerge because at least two individuals find it in their interest to start engaging in exchange. Whereas it is usually in the interest of the original market partners to exclude others from entering their own side of the market, it is equally in their interest to invite others to enter the opposite side of the market. Suppliers will try to keep other suppliers out but like to be faced by more demanders, and the same is true of the demand side. This is so provided those engaging in exchange understand that it is in their interest to keep a particular market in existence. Or, as Loasby observes,

'Arrangements which facilitate transactions often create externalities. They will almost always do so when the arrangements are designed to create a continuing transaction capability - in order words a market - which is accessible to many.' (Loasby, 1994, p. 9).

This is part of the mechanism through which more and more individuals become involved in the market. The external effect of a newly established may may consist of the fact that it serves as an example that can be imitated by others. Once individuals stop behaving as one-shot maximizers, a market infrastructure may establish itself where there was none before. These external effects are a type of social amplifier, a mechanism that acts as a generator of value. Not only will needs be satisfied that could not be satisfied previous to the emergence of a market system, new needs will be created as well. And whatever one's subjective opinion of the intrinsic value of such newly discovered needs, they open up opportunities for an increasing number of other individuals to participate in the social game of value creation.

\subsection{Stability and the past}

A system in transition needs both change and stability. Social institutions and the texture of institutions that make up a society are such a complex whole of relationships and processes that we are just beginning to understand how they work. Hayek argues that evolved institutions constitute a stock of social capital that it took a long time to accumulate. Applied to the formerly communist societies this means that destroying the habits and other institutions that have evolved over the last 75 years is a destruction of social capital that may have (and already did have) disastrous consequences. The results of such a long evolution cannot be abolished from one day to another. Doing so would leave a society without any kind of stability, a very dangerous situation. This is the mistake Gorbatsjov made. Under the old structure there was at least some knowledge of the sort of behaviour patterns one could expect. This explains why in almost every formerly communist country the former communists were re-elected in the first free elections. It was not because the voters wanted communism back. All they wanted was some stability. Given the alternatives, their voting behaviour is entirely rational. Having some structure, however unsatisfactory, 
is better than having no structure at all. Under the old structure there was at least some knowledge of the sort of behaviour patterns one could expect.

The history of a society matters for its future development. There is a division between on the one hand countries that have within living memory had an entrepreneurial tradition and on the other hand those that have been centrally ruled for much longer. Transplanting a social system that has evolved and proven satisfactory in one culture to another may have disastrous consequences. The underlying traditions have to match. If we were given the time for introducing changes in Eastern Europe at a more prudent pace, we would first have to apply historical analysis in order to discover what may be called the social constants of the various societies. Social constants may be defined as behaviour patterns that are resistant to change, except perhaps in the long run. For instance, in Russia the revolution of 1917 did not so much change the social structure (which had been centralist for a long time under the czars) as the ideology. Of course, over time, this ideology helped to create a social structure that might not have evolved under the czars, but this is something we will never know.

\section{Conclusion: finding the boundaries of the controllable}

If one wants to change, one has to start somewhere, and even in an evolutionary framework respect for stability has to go hand in hand with a vision on the goals we set out to achieve and the means we can apply. It lies in the nature of the complex evolutionary mechanism of society that the number of detailed measures one can take, the number of variables one seeks to control, is limited. The problem is to find the boundaries of the controllable. Hayek is certainly correct in drawing attention to the fact that what enters into this complex of problems is the notion of unintended effects. But as we have seen, unintended effects may to a certain extent be predictable. This creates a space for some social engineering. The conservative radicalism of Hayek's later work is unfounded, and an approach such as the gradualism of Popper's open Society is defensible on Hayekian terms. It is in this light that one may try to implement Bianchi's proposal and introduce a type of social framework which favours the ability to learn. The creation of conditions under which this is rendered most probable may benefit from the type of empirical research that is done in sociological network theory. Enhancing the probability that individuals will establish and maintain weak ties will be conducive to the 'amendable society' that Bianchi advocates. Such an open society has to be supported by an adequate legal and political framework. In the end, for the former communist countries it is not the introduction of the market that is of the highest importance. It is more important to find a system which is both more adapted to each country's specific history and more adaptable to unforeseeable future developments. It is likely that this is a decentralized system, but insisting that it must be an exact copy of the market society of the West is as dogmatic as the one-time defence of centralized planning by Marxists. 


\section{Notes}

1. Cp. Hayek, 1945, para. 2 .

2. His other main contributions to business cycle theory can be found in Prices and Production and Profits, Interest and Investment.

3. Thus Hayek uses the term "forced saving" to indicate a situation in which consumers cannot fulfill their plans.

4. For a detailed discussion of the contributions by Hayek, and of those by Mises, to the debate on socialism, cp. Keizer, 1994 .

5. The most important early publications are the collection of essays in Hayek, 1949, and Hayek, 1960. In his later work Hayek is markedly more conservative in his conclusions. Cp. Hayek, 1973, 1967, 1979, and Hayek, 1988.

6. The references in the text are to the edition in Hayek, 1949 .

7. This is very similar to Popper's approach to social science. Watkins has coined the term "negative utilitarianism" for this.

8. Cp. for instance Hayek, 1955a, 1963, 1964 and 1967.

9. As the published version of (1952) contains the basic ideas of the manuscript of 1920, all references will be to the book.

10. Cp. Simon, 1968 .

11. I observe once more that up to and including constitution of Liberty Hayek is more open to the possibility of

intervening in social institutions than in his later work. I will return to this in the paragraph 'Prediction and stability' below.

12. Cp. for instance George, 1961, p. 112: 'The idea that the human senses worked on a classification principle had

previously been suggested by Hayek (1952), and Uttley was able to build a simple classification system in hardware.' Cp. also ibid., p. 319, and Rosenblatt, 1958, p. 92.

13. Burt does not refer to Hayek (nor to Mises).

14. Cp. Hayek, 1945, p. 86.

15. Granovetter has concentrated on the labour market. With the exception of Burt, 1992, there have been no attempts to 
describe the functioning of markets in general in network models. The present author is engaged in a research project with that scope.

16. Cp. Plant, 1994 .

17. Cp. Kirman, 1983. Cp. also Garretsen, 1994 and Van Zijp \& Visser, 1994.

18. Cp. Robinson, 1956, and also Hayek, 1941. This criticism is a variant of the criticism of the representative-

individual model. Hayek starts with an idealized dictatorled economy and then subsequently introduces more decentralized decision making. This makes that book

compulsory reading for all those interested in issues of economic decentralization.

19. The problem of the reproduction of markets in such a subjectivist contextis analyzed in White, 1988.

20. The word 'construction' must not be read as referring to a deliberate action; this is equally the case with the first sense. Contrary to the views of Mises and Hayek, it is not necessary for networks to exist that actors be aware of their attitudes.

21. Desai even argues that the free market society was the deliberate creation of the English state. Less

controversially, he observes that when the philosopher who

is now almost universally hailed as the theorist of the free market was writing, there was no market society yet. Smith's arguments in favour of such a society were as theoretical as are the arguments by Arrow and Debreu for the invisible hand theorem. Cp. Desai, 1986.

22. Cp. for instance Desai, 1986. 


\section{Literature}

J.A. Anderson \& E. Rosenfeld (1988), Neurocomputing. Foundations of Research, MIT Press

W. Arts, S. Lindenberg en R. Wippler (red.) (1976), Gedrag en Struktuur, De relevantie van microtheorieën voor de verklaring van macroverschijnselen, Special issue of Mens en Maatschappij, Universitaire Pers Rotterdam

M. Bianchi (1994), 'Hayek's Spontaneous Order: The "Correct" versus the "Corrigible" Society', in Birner \& Van Zijp, 1994

J. Birner \& R. Van Zijp (eds.) (1994), Hayek, Co-ordination and Evolution. His legacy in philosophy, politics, economics and the history of ideas, Routledge

R. S. Burt (1992), Structural Holes. The Social structure of Competition, Harvard University Press

M. Desai (1986), 'Men and Things', Economica

H.D. Flap (1976), 'De kracht van zwakke bindingen of de zwakte van sterke bindingen', in Arts, Lindenberg \& Wippler, 1976

H. Garretsen (1994), 'The Relevance of Hayek for Mainstream Economics', in Birner \& Van Zijp, 1994

F.H. George (1961), The Brain as a Computer, Pergamon Press

M. Granovetter (1982), 'The Strength of Weak Ties; A Network Theory Revisited', in Marsden \& Lin, 1982

F.A. Hayek (1928), 'Das intertemporale Gleichgewichtssystem der Preise und die Bewegungen des "Geldwertes"', Weltwirtschaftiches Archiv

F.A. Hayek (1931), Prices and Production, Routledge \& Kegan Paul

F.A. Hayek (ed.) (1935), Collectivist Economic Planning. Critical Studies on the Possibilities of Socialism By N.G. Pierson, Ludwig v. Mises, Georg Halm \& Enrico Barone, Edited with an introduction and a concluding essay by Friedrich A. Hayek, Augustus M. Kelley 1975

F.A. Hayek (1937), 'Economics and Knowledge', in Hayek, 1949

F.A. Hayek (1939), Profits, Interest and Investment and other Essays on the Theory of Industrial Fluctuations, Routledge

F.A. Hayek (1941), The Pure Theory of Capital, Routledge \& Kegan Paul

F.A. Hayek (1945), 'The Use of Knowledge in Society', in Hayek, 1949 
F.A. Hayek (1946), 'The Meaning of Competition', in Hayek, 1949

F.A. Hayek (1947), '"Free Enterprise" and Competitive Order', in Hayek, 1949

F.A. Hayek (1949), Individualism and Economic Order, Routledge \& Kegan Paul

F.A. Hayek (1952), The Sensory Order. An Inquiry into the $\underline{\text { O }}$

F.A. Hayek (1955), The Counterrevolution of Science, The Free Press

F.A. Hayek (1955a), 'Degrees of Explanation', in Hayek, 1967a

F.A. Hayek (1960), The Constitution of Liberty, Routledge \& Kegan Paul

F.A. Hayek (1963), 'Rules, Perception and Intelligibility', in Hayek, $1967 a$

F.A. Hayek (1964), 'The Theory of Complex Phenomena', in Hayek, $1967 a$

F.A. Hayek (1965), 'Kinds of Rationalism', in Hayek, 1967a 
F.A. Hayek (1967), 'Notes on the Evolution of Systems of Rules of Conduct', in Hayek, $1967 \mathrm{a}$

F.A. Hayek (1967a), Studies in Philosophy, Politics and $\underline{E}$

$\underline{\mathrm{on}}$

$\underline{\mathrm{om}}$

$\underline{i c}$

$\underline{\mathrm{s}}$,

$\mathrm{U} n$

i $\mathrm{V}$

e r

s i

t $y$

of

$\mathrm{C} \mathrm{h}$

i $\mathrm{C}$

a 9

$\mathrm{O}$

P r

e s

$\mathrm{S}$

F.A Hayek (1968), 'Competition as a Discovery Procedure', in Hayek, 1978

F.A. Hayek (1973), Law, Legislation and Liberty. Volume 1, Rules and Order, Routledge \& Kegan Paul

F.A. Hayek (1976), Law, Legislation and Liberty. Volume II, The Mirage of Social Justice, Routledge \& Kegan Paul

F.A. Hayek (1978), New Studies in Philosophy, Politics, Economics and the History of Ideas, Routledge \& Kegan Paul

F.A. Hayek (1979), Law, Legislation and Liberty. Volume III, The Political Order of a Free People, Routledge \& Kegan Paul

F.A. Hayek (1988), The Fatal Conceit. The Errors of Socialism, Routledge

W. Keizer (1994), 'Hayek's Critique of Socialism', in Birner \& Van Zijp, 1994

A. Kirman (1983), 'Communication in Markets; A Suggested A p 
$\underline{\mathrm{S}}$

B.J. Loasby 1994, 'Understanding Markets', unpublished paper

P. Marsden \& N. Lin (eds.) (1982), Social Structure and Network Analysis, Sage

L. Von Mises (1920), 'Economic Calculation in the Socialist Commonwealth', in Hayek, 1935

J.L. McClelland, D.E. Rumelhart \& G.E. Hinton (1986), 'The Appeal of Parallel Distributed Processing', in Rumelhart \& McClelland, 1986, Vol. I

R. Plant (1994), 'Hayek on Social Justice: A Critique', in Birner \& Van Zijp, 1994

K.R. Popper (1945), The Open Society and its Enemies, Routledge \& Kegan Paul

J. Robinson (1956), The Accumulation of Capital, MacMillan

F. Rosenblatt (1958), 'The perceptron: a probabilistic model for information storage and organization in the brain', in Anderson \& Rosenfeld, 1988

D.E. Rumelhart, J.L. McClelland and the PDP Research group ( 1 
H.A. Simon (1969), The Sciences of the Artificial, MIT Press

A. Smith (1759), The Theory of Moral Sentiments, With an In

R. de Vries (1994), 'The Place of Hayek's Theory of Mind and Perception in the History of Philosophy and Psychology', in Birner \& Van Zijp, 1994

B. Wellman \& S.D. Berkowitz (eds.) (1988), Social Structure: A Network Approach, Cambridge University Press

H.C. White (1988), 'Varieties of markets', in Wellman \& Berkowitz, 1988 
R. van Zijp \& H. Visser (1994), 'Mathematical Formalization and the Domain of Economics: the Case of Hayek and New Classical Economics', in Birner \& Van Zijp, 1994 